\title{
Aerial Transmission of Thielaviopsis basicola, a Pathogen of Corn-Salad, by Adult Shore Flies
}

\author{
M. E. Stanghellini, S. L. Rasmussen, and D. H. Kim
}

First and third authors: Department of Plant Pathology, University of California, Riverside 92521; and second author: Department of Plant Pathology, University of Arizona, Tucson 85721.

Accepted for publication 8 March 1999.

\begin{abstract}
Stanghellini, M. E., Rasmussen, S. L., and Kim, D. H. 1999. Aerial transmission of Thielaviopsis basicola, a pathogen of corn-salad, by adult shore flies. Phytopathology 89:476-479.

Chlamydospores of Thielaviopsis basicola were consistently observed in frass excreted by adults and larvae of shore flies that were collected in the immediate vicinity of naturally infected corn-salad plants obtained from a commercial greenhouse production facility. Approximately $95 \%$ of the adult flies and $85 \%$ of the larvae were internally infested with the patho-
\end{abstract}

ABSTRACT gen. Pathogen-free adult shore flies were subsequently shown to acquire the pathogen by ingestion after feeding on naturally infected plants. Viable propagules of the pathogen were excreted by these internally infested adults and were capable of transmitting the pathogen to healthy seedlings, which subsequently became infected.

Additional keywords: fungus gnats, hydroponics, insect vector, Pythium aphanidermatum, soilborne plant pathogen.
Avoidance of root-infecting, soilborne plant pathogens was one of the motivating forces underlying the development of the soilless cultural system known as hydroponics. Although cultivation in hydroponics has resulted in a decrease in the diversity of rootinfecting pathogens compared with conventional culture in soil, root diseases still occurred (5). Infectious agents, once introduced into a hydroponic system, are favored as a result of (i) the abundance of a genetically uniform crop and (ii) a more constant physical environment, especially temperature and moisture. Thus, maintenance of a pathogen-free cultivation system is dependent upon identification and elimination of the source(s) responsible for the introduction of root-infecting pathogens.

Thielaviopsis basicola (Berk. \& Broome) Ferraris (=Chalara elegans Nag Raj \& Kendrick), a soilborne, root-infecting pathogen, was identified in 1988 as the causal agent of root and stem rot of corn-salad plants (Valerianella locusta (L.) Betcke, a 'gourmet' green leafy plant used in salads) in a commercial hydroponic production facility in Pennsylvania (6). Despite extensive sanitation measures, the disease reoccurred in this facility in 1993. On diseased plants received for diagnosis from the commercial facility, we noted that infections appeared to originate on the above-ground portions of plants (i.e., the lower stems that were necrotic) and progress down the taproot. Secondary and tertiary roots were white and appeared healthy. Additionally, we noted that the plants were heavily infested with adult shore flies (Scatella stagnalis Fallen). These observations suggested that adult shore flies may be involved as an aerial vector for T. basicola. Adult shore flies have previously been implicated experimentally as a potential aerial vector of $P y$ thium aphanidermatum (Edson) Fitzp., a destructive root pathogen of hydroponically grown cucumbers (2).

Our objectives were to determine if shore flies obtained from the commercial production facility were infested with the pathogen and to assess the ability of the insects to acquire and transmit the pathogen to healthy plants. A preliminary report has been published (7).

Corresponding author: M. E. Stanghellini; E-mail address: mstang@ucrac1.ucr.edu

Publication no. P-1999-0412-01R

(C) 1999 The American Phytopathological Society

\section{MATERIALS AND METHODS}

Natural infestation levels. Various life stages of the shore fly (including larvae, pupae, and adults) were collected daily, over a 5-day period, in the immediate vicinity of naturally infected plants obtained from the commercial facility. Shore flies in their different life stages occurred in abundance on the roots and lower stems of these plants. Individual larvae and adult insects were captured by aspiration and caged in petri dishes containing solidified $2 \%$ water agar (Difco Laboratories, Detroit). After a 24-h incubation period, frass deposits excreted on the agar surface by these two life stages were enumerated and microscopically examined for the presence of chlamydospores of the pathogen. Additionally, larvae and pupae were collected, gently squashed, and examined microscopically for chlamydospores in the intestinal tract of each life stage. External surfaces of the various life stages of the shore fly were not examined for the presence of the fungus.

Acquisition and transmission studies. Twenty pathogen-free adult shore flies, obtained from a colony that we maintain in a greenhouse, were captured and caged in small chambers containing naturally infected corn-salad seedlings. Microscopic examination revealed the presence of intact chains of chlamydospores of the pathogen on the lower stem (hypocotyl) of infected plants (Fig. 1). Endocondia were seldom observed. Immediately prior to the introduction of the pathogen-free adult shore flies, all naturally occurring adults and pupae were physically removed from the naturally infected seedlings. The introduced adult flies, after an incubation period of $24 \mathrm{~h}$, were recaptured via aspiration. Ten of the recaptured adults were then individually caged in petri dishes containing solidified water agar and assessed for presence of the pathogen in excreted frass. The remaining 10 adults were caged in a chamber containing six healthy, 2-week-old, corn-salad seedlings. The latter seedlings, which were grown under hydroponic conditions in rockwool cubes, were then placed in a growth chamber at $20^{\circ} \mathrm{C}$ with a 12-h photoperiod. The above experiment was repeated once. However, in the second experiment, 6 of the 20 adult insects were recaptured after a $4-\mathrm{h}$ acquisition period and 4 adults were recaptured after a 24-h acquisition period and assessed, as described above, for the presence of the pathogen in excreted frass. The 10 re- 
maining adults were used for transmission studies as previously described. Controls in each experiment consisted of 10 pathogenfree adult shore flies caged on six healthy corn-salad seedlings.

\section{RESULTS}

Natural infestation levels. A total of 22 adult insects were captured in the vicinity of naturally infected plants and placed individually in petri dishes. Microscopic examination of frass excreted by these adults revealed that 21 of the adults (approximately 95\%) were internally infested with $T$. basicola (Table 1). Chlamydospores of the fungus were readily observed in frass excreted by these

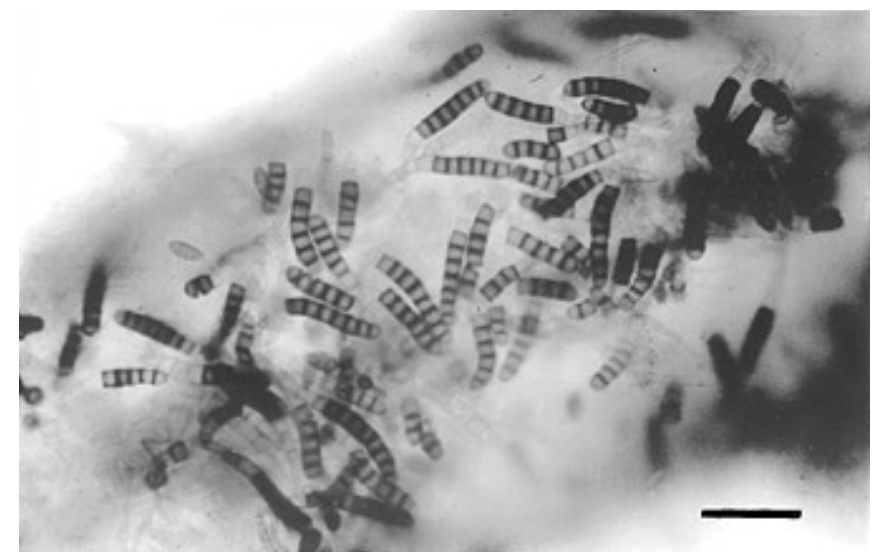

Fig. 1. Chlamydospores of Thielaviopsis basicola on a naturally infected stem of a corn-salad plant (bar $=150 \mu \mathrm{m})$. adults. The chlamydospores in excreted frass consisted primarily of individual cells, but intact chains of chlamydospore cells were occasionally observed (Fig. 2A). The number of chlamydospores of T. basicola per frass deposit varied from 10 to 120 per frass deposit. Internally infested adults excreted approximately six frass deposits per insect, of which $73 \%$ contained the pathogen (Table 2). Chlamydospores of the fungus in frass deposits germinated within $48 \mathrm{~h}$ (Fig. 2B). No attempt was made, however, to quantify the percentage of viable chlamydospores. However, all colonies of $T$. basicola on the plates originated solely from frass deposits.

Approximately $85 \%$ of the larvae collected in the vicinity of naturally infected plants were internally infested with the fungus (Table 1). Chlamydospores of the fungus were readily observed in the intestinal tract of squashed larvae (Fig. 2C) and in the frass excreted by the larvae (Fig. 2D). Excreted spores were viable and germinated within $48 \mathrm{~h}$. All colonies of the pathogen on the water agar plates originated from frass deposits.

TABLE 1. Percent of shore fly life stages internally infested with Thielaviopsis basicola $^{\mathrm{a}}$

\begin{tabular}{lccc}
\hline Shore fly life stage & No. sampled & No. infested & Percent infested \\
\hline Adult flies $^{\mathrm{b}}$ & 22 & 21 & 95.4 \\
Larvae $^{\mathrm{c}}$ & 20 & 17 & 85.0 \\
Pupae $^{\mathrm{c}}$ & 28 & 4 & 14.2 \\
\hline
\end{tabular}

${ }^{a}$ Naturally occurring life stages were collected in the immediate vicinity of naturally infected corn-salad plants from a commercial production facility.

${ }^{\mathrm{b}}$ Chlamydospores of Thielaviopsis were microscopically observed in frass deposits.

${ }^{\mathrm{c}}$ Chlamydospores of Thielaviopsis were microscopically observed in the intestinal tract.

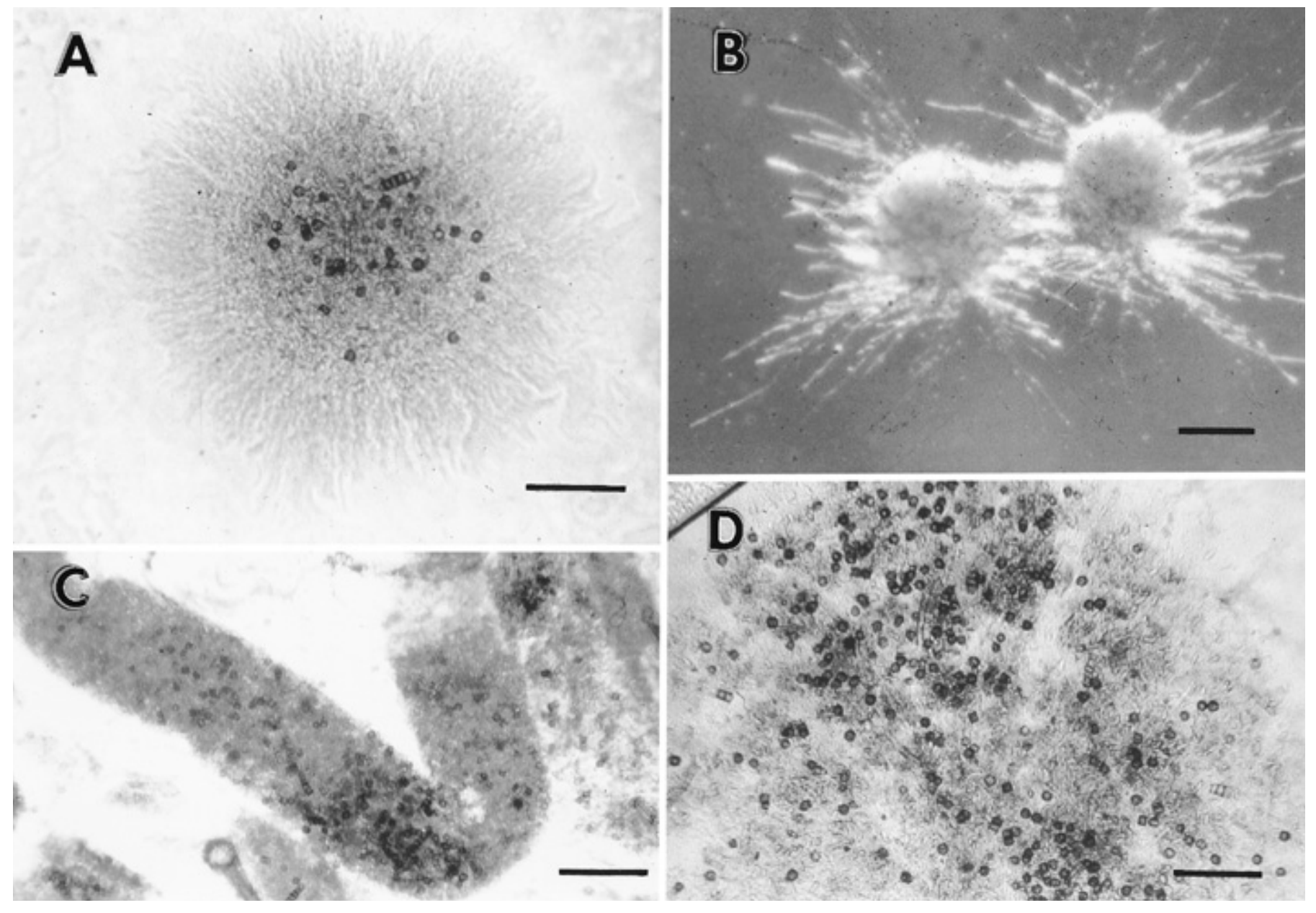

Fig. 2. Intact and fragmented chlamydospores of Thielaviopsis basicola $\mathbf{A}$, in frass excreted by adult shore flies (bar $=200 \mu \mathrm{m}$ ); B, germinating in frass excreted by an adult shore fly $(\mathrm{bar}=500 \mu \mathrm{m}) ; \mathbf{C}$, in the intestinal tract of a larva of a shore fly $(\mathrm{bar}=200 \mu \mathrm{m})$; and $\mathbf{D}$, in frass excreted by a larva of a shore fly $(\mathrm{bar}=250 \mu \mathrm{m})$. 
In contrast to both larvae and adult flies, only $14 \%$ of the pupae were observed to be internally infested with the fungus (Table 1). Viability of spores in the gut of pupae was not determined.

Pathogen acquisition. Two separate acquisition experiments, involving 20 adult flies, were conducted (Table 3 ). In experiment 1 , frass deposits from 9 of 10 adult insects contained the fungus. One adult did not excrete during the $24-\mathrm{h}$ incubation period. In the second experiment, six insects were recaptured after a 4-h acquisition period and four were recaptured after $24 \mathrm{~h}$. All insects, irrespective of the duration of incubation, were internally infested, as evidenced by the presence of chlamydospores in excreted frass. A high percentage of the frass deposits excreted by these adults (approximately 93\%) contained chlamydospores (Table 2).

Transmission studies. Within $10 \mathrm{~min}$ after caging internally infested adults on healthy seedlings, frass deposits were observed on the lower stem of these seedlings (Fig. 3). Microscopic examination of frass deposits on the lower stem revealed the presence of chlamydospores of the pathogen. Disease symptoms (i.e., necrosis and blackening of the lower stems) were observed between 14 to 21 days later on four of six 'insect-inoculated' plants in the first experiment and three of six 'insect-inoculated' plants in the second experiment. T. basicola was consistently reisolated from symptomatic plants. Respective control plants remained healthy and the fungus was not isolated from these plants.

\section{DISCUSSION}

The results of this investigation provide the first documented evidence from a commercial production facility that adult shore flies may be involved in the aerial transmission of T. basicola. A high percentage of the naturally occurring population of adult shore flies $(95 \%)$ and of the larvae (85\%), which were collected in the immediate vicinity of naturally infected plants, were shown to be internally infested with T. basicola. Chlamydospores of the pathogen were readily observed in the intestinal tract of larvae and in frass excreted by these naturally infested larvae and adults flies. The low percentage of internally infested pupae and the high percentage of internally infested adults suggested that the adult shore

TABLE 2. Prevalence of Thielaviopsis basicola in frass deposits excreted by internally infested adult shore flies

\begin{tabular}{|c|c|c|}
\hline & Population $\mathrm{A}^{\mathrm{a}}$ & Population $\mathrm{B}^{\mathrm{b}}$ \\
\hline Number of flies assayed & 22 & 20 \\
\hline Number of flies infested & 21 & 19 \\
\hline Frass deposits/adult population & 134 & 72 \\
\hline Frass deposits infested/adult population & 97 & 67 \\
\hline Frass deposits infested/adult population (\%) & 72.3 & 93 \\
\hline Frass deposits/insect (mean $\pm \mathrm{SE}$ ) & $6.0 \pm 0.7$ & $3.7 \pm 0.6$ \\
\hline Frass deposits infested/insect (mean $\pm \mathrm{SE}$ ) & $4.4 \pm 0.6$ & $3.5 \pm 0.6$ \\
\hline Frass deposits infested/insect (\%) & 73.3 & 94.5 \\
\hline
\end{tabular}

a Population A consisted of a naturally infested population of adult flies collected in the immediate vicinity of diseased seedlings from a commercial greenhouse.

b Population B consisted of Thielaviopsis-free adult flies that were placed on diseased seedlings for 4 or $24 \mathrm{~h}$ and then captured by aspiration and assayed.

TABLE 3. Acquisition of Thielaviopsis basicola by pathogen-free adult shore flies after feeding on naturally infested corn-salad plants

\begin{tabular}{lccc}
\hline & Acquisition time $(\mathrm{h})^{\mathrm{a}}$ & No. sampled & No. infested \\
\hline Experiment 1 & 24 & 10 & 9 \\
Experiment 2 & 4 & 6 & 6 \\
& 24 & 4 & 4 \\
\hline
\end{tabular}

a Following various acquisition time periods, adults were captured and individually caged in petri dishes containing water agar. Frass deposits per adult fly were enumerated and visually inspected for the presence of chlamydospores of the pathogen. flies acquired the fungus by direct feeding. Experiments employing pathogen-free adults, which were allowed to feed on infected plants, documented that adult shore flies can acquire the fungus by direct feeding. These results are in contrast to a previous greenhouse study on shore flies and P. aphanidermatum (2). In the latter study, a high percentage of larvae were internally infested with the fungus and a low percentage of adults were internally infested. The difference between the levels of infestation of these two life stages may reside in insect access to infected plant tissue colonized by the pathogen. In the case of $P$. aphanidermatum, adult shore flies did not have access to infected roots, which contain the reproductive and survival structures (i.e., oospores) of the pathogen. Larvae, on the other hand, feed in or on infected roots containing oospores, and thus acquired the fungus. Residual oospores retained in the gut of larvae following pupation may account for the low percentage of internally infested adults. In the case of Thielaviopsis, abundant sporulation of the pathogen (i.e., chlamydospores) occurs on the hypocotyl of infected plants. Sporulation of the pathogen on above-ground plant parts provides a readily accessible source for pathogen acquisition by adult shore flies. Our studies showed that adult shore flies can acquire the fungus within hours after feeding on infected hypocotyls bearing chlamydospores of $T$. basicola and that these internally infested adult shore flies can function as an aerial vector for transmission of the pathogen. Frass deposits containing viable propagules of the fungus were observed within minutes on the hypocotyl of seedlings visited by internally infested adults. Fifty to sixty percent of the plants, in two separate experiments, developed disease symptoms within 14 to 21 days. Additionally, passage of chlamydospores through the intestinal tract of adults and larvae may enhance germination. Intact chains of chlamydospores were observed on stems and roots of naturally infected corn-salad seedlings. However, most of the chlamydospores observed in the intestinal tract of larvae and in frass excreted by adults and larvae were fragmented into individual cells. Patrick et al. (4) reported that fragmentation of chlamydospores into separate cells appeared to be necessary for germination. Deposition of chlamydospore-laden frass by adult shore flies on the lower stems of susceptible plants would essentially guarantee a high probability of host infection.

In addition to shore flies, fungus gnats (Bradysia impatiens) have also been implicated as potential vectors of certain plant pathogens of hydroponically grown crops. Specifically, adult fungus gnats

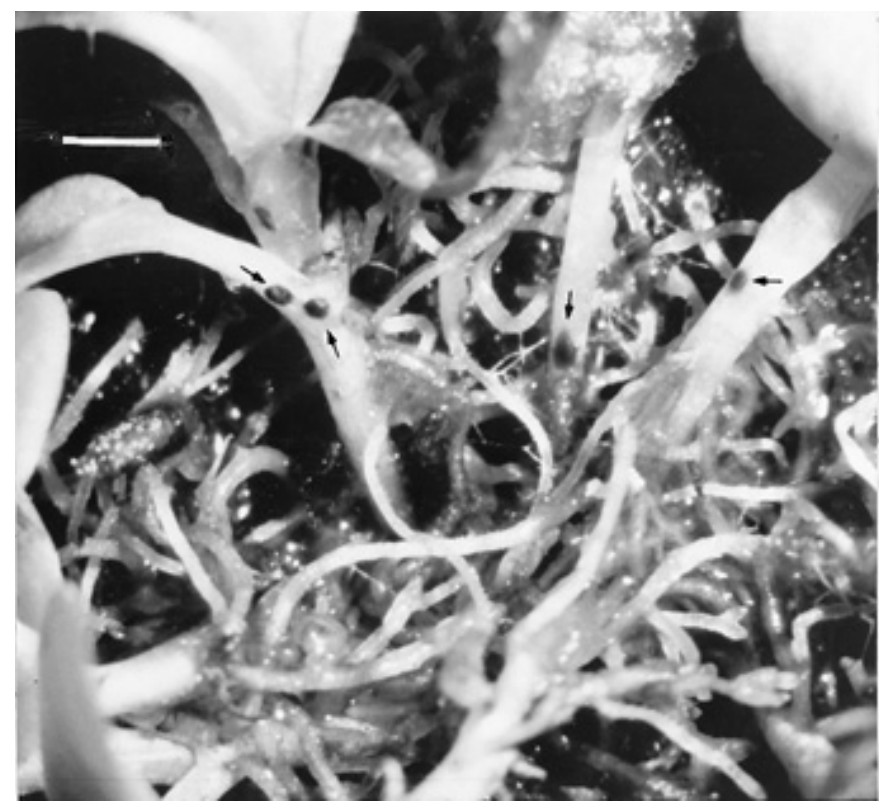

Fig. 3. Adult shore fly frass deposits (arrows) on the hypocotyl of corn-salad seedlings $(\mathrm{bar}=5 \mathrm{~mm})$. 
have been implicated as a potential aerial vector of Fusarium oxysporum f. sp. radicis-lycopersici on tomato (1). However, the method of pathogen acquisition by adult fungus gnats was not reported. Studies by Jarvis et al. (3) demonstrated that larvae of fungus gnats can ingest and excrete viable oospores of $P$. aphanidermatum and transmit the pathogen to healthy cucumber plants, which subsequently became infected. Adult fungus gnats, however, did not ingest the fungus and were not regarded as a potential aerial vector of $P$. aphanidermatum.

Shore flies and fungus gnats are the most abundant insects in commercial hydroponic facilities. The cumulative results of the above studies suggest that various life stages of both insects, which have historically been considered merely a nuisance, could function as a source of pathogen introduction into a commercial hydroponic facility. Whether or not they are significantly involved in the subsequent spread of the pathogen within a facility remains to be documented.

\section{LITERATURE CITED}

1. Gillespie, D. R., and Menzies, J. G. 1993. Fungus gnats vector Fusarium oxysporum f.sp. radicis-lycopersici. Ann. Appl. Biol. 123:539-544.

2. Goldberg, N. P., and Stanghellini, M. E. 1990. Ingestion-egestion and aerial transmission of Pythium aphanidermatum by shore flies (Ephydrinae: Scatella stagnalis). Phytopathology 80:1244-1246.

3. Jarvis, W. R., Shipp, J. L., and Gardiner, R. B. 1993. Transmission of Pythium aphanidermatum to greenhouse cucumber by the fungus gnat Bradysia impatiens (Diptera: Sciaridae). Ann. Appl. Biol. 122:23-29.

4. Patrick, Z. A., Toussoun, T. A., and Thorpe, H. J. 1965. Germination of chlamydospores of Thielaviopsis basicola. Phytopathology 55:466-467.

5. Stanghellini, M. E., and Rasmussen, S. L. 1994. Identification and origin of plant pathogenic microorganisms in recirculating nutrient solutions. Adv. Space Res. 14:349-355.

6. Stanghellini, M. E., Rasmussen, S. L., and Barta, D. J. 1990. Thielaviopsis root rot of corn-salad. Plant Dis. 74:81.

7. Stanghellini, M. E., Rasmussen, S. L., and Kim, D. H. 1994. Ingestion-egestion and aerial transmission of Thielaviopsis basicola, a root and stem pathogen of corn-salad, by adult shore flies. (Abstr.) Phytopathology 84:1066. 